\author{
MERENIA GRAY, JENNY STEVENSON, AND \\ TANEMAHUTA GRAY
}

\title{
Postscript: Starter questions for a Postscript posed by Peter Cleave and answered by Merenia Gray, Jenny Stevenson and Tanemahuta Gray.
}

Professor Peter Cleave (Wolfson College, Oxford), is a widely-published New Zealand academic, currently focusing on issues relating to contemporary as well as historical Maori development

Merenia Gray is is an Associate of the Imperial Society of Teachers of Dance and holds an Advanced Royal Academy of Dance certificate. Merenia has taught both abroad and in New Zealand (at the New Zealand School of Dance, Toi Whakaari New Zealand Drama School, the Wellington Performing Arts Centre and at Whitireia, Dansens Hus in Copehagen and Studio Harmony in Paris). She is the founding director of Raising The Barre - Freelance dance classes for Wellington Professionals at the Royal New Zealand Ballet studios.

Jenny Stevenson is graduated from the then New Zealand Ballet School, later the New Zealand School of Dance in 1968. Jenny danced with the New Zealand Ballet Company and then the Australian Dance Theatre. Between 1987 and 2008 Jenny founded and managed the Wellington Performing Arts Centre. From 2001 to 2011 Jenny has been a dance critic and commentator for Radio New Zealand. In March - July 2011, Jenny was engaged by Wellington City Council and DANZ to create the draft format for the Wellington Dance Festival in 2012, and created the Festival Launch Programme in July, 2011 and also created a Wellington Dance Festival Programme for a proposed 2012 festival.

Tanemahuta Gray took up the role of Maori Dance Tutor at the New Zealand School of Dance in May of 2012. He was the Contemporary and Maori Cultural tutor at Whitireia Performing Arts in Wellington in 2009-10 and accompanied them to Slovenia, Croatia and Germany on the CEOFF Festival Tour in Europe in July 2010. He is an ex board member with Taki-Rua Productions, and currently chairman of Kapiti Kids Motivational Trust. Tanemahuta also teaches Maori and Kapa Haka part-time at Te Ra Waldorf Steiner School, and teaches a New Maori Dance Course at Kapiti College, Otaki College and Wellington College, alongside numerous workshops in schools for DANZ. 
Merenia responds:

\section{Looking back at Kowhiti Atarau 2013 is there one thing that stands out in your mind?}

I was totally taken aback at the dress rehearsal of what we had curated. The high quality of the choreography and dancers aligned with the digital effects from a lot of the work was one of the best dance shows I'd seen in over five years.

2. What were your intentions with Kowhiti Atarau? What did you want it to be?

We wanted to highlight the wealth and quality of both national and international contemporary indigenous dance practitioners from stage to page.

3. Was Kowhiti Atarau different in any way, positive or negative than what you wanted it to be?

It was by far the richest of high quality and emerging work presented of the three seasons. Unfortunately the directors didn't get any remuneration for this season.

4. Were such matters as the venues, the time of the year or the scheduling of papers satisfactory to you?

The venues and time of year were fine, but hosting it all under the one venue would be ideal for the future.

5 comment if you want to on the combination of practitioners and academics at Kowhiti Atarau.

The combination was enriching for all involved and better programming for the symposium will assist in the future. Time and space (money) were limited. However, it has set a precedent in which Kowhiti can only learn and grow from. 


\section{What for you was the learning in Kowhiti Atarau?}

Embassies have money and the right pitch certainly helps to attract sponsors. Donor relations are key to maintain from season to season.

\section{Are there any other points you might like to make?}

Working with Jenny and Tane is amazing and we made a dream team. We are currently focusing on our individual projects and this will give us time to learn and grow so that Kowhiti can go from strength to strength.

\section{Where to now for Kowhiti?}

Kowhiti should look to maintaining a public eye through publication of the symposium through online dance journals and indigenous pathways.

The connection with Dancing Earth and The US Embassy is a key factor for a US tour in the future.

A new active Director is required to keep the Kowhiti Brand alive, to assist Jenny in an Auckland season.

Kowhiti should look to align its self with both the NZ Arts Festival and The Auckland Arts Festival, Wellington Dance Festival and Tempo Dance Festival, by initially sponsoring a choreographer to create a new work for any of the above festivals. This will keep the brand alive in the arts/dance practical scene.

Merenia has a new role as the Development Manager for the NZDC and in time should that role expand there may be room to align Kowhiti's involvement with sharing rehearsal space, marketing, triple bills. (Thoughts only at this stage).

Tane's new work could well be one work that Kowhiti supports through gaining funds and acts as a production company to support his vision.

Merenia's film work Hine Ahu One could also be presented 
under the Kowhiti Banner for marketing and presentation purposes.

I do believe Kowhiti is a brand worth cherishing and thank you for this opportunity to deliver these ideas.

Nga mihi nui

Merenia Gray.

Jenny responds:

\section{Looking back at Kowhiti Atarau 2013 is there one thing that stands out in your mind?}

It would definitely have to be the first day - when everyone was welcomed formally, followed by a series of wonderful informal introductions by everyone who was present. The atmosphere was fantastic and I think it set the tone for the rest of the festival.

\section{What were your intentions with Kowhiti Atarau? What did you want it to be?}

It was very much an "indigenous peoples" festival and this certainly for me was what I had hoped to achieve. I was also very keen to include the academic symposium and Merenia and Tanemahuta were kind enough to support me in this venture.

\section{Was Kowhiti Atarau different in any way, positive or} negative than what you wanted it to be?

It was full of surprises for me! I thought the performance programme that we curated for the Opera House was very exciting to watch from a dance point of view, but I was also 
very pleased with the emerging artists programme on Te Marae at Te Papa on the last day. It was a great way to finish.

\section{Were such matters as the venues, the time of the year or} the scheduling of papers satisfactory to you?

We were very fortunate to have been supported for the first day of the Symposium by Whitireia New Zealand as it would not have been financially viable to have had two days at Te Papa. In retrospect the scheduling of papers side-by-side in two different venues on the second day did not work too well as people were forced to choose between two very interesting topics on several occasions.

The time of year worked well in that we were able to partner with Dance Wellington to be the opening event of their inaugural festival.

5 comment if you want to on the combination of practitioners and academics at Kowhiti Atarau

I found this aspect of Atarau to be very interesting - but as several people commented to me - there was not enough opportunity for the two groups to get together as all the practitioners were focusing on their performances.

\section{What for you was the learning in Kowhiti Atarau?}

It was very exciting to see people from different cultures united by the language of dance. When I was watching the performance for school-children I could see how they instinctively embraced this concept.

\section{Are there any other points you might like to make?}

We are so grateful for the generosity of the United States Embassy in bringing Dancing Earth to New Zealand. It enabled us to host a fantastic group of First Nation dancers who contributed so much to the festival by their presence. 


\section{Where to now for Kowhiti?}

There is a possibility of holding another festival in Auckland at some stage but the Directors of Kōwhiti are taking time out at the moment to concentrate on other projects. We are very happy with what we have achieved to date in producing three festivals and an academic symposium.

Tanemahuta responds:

\section{Looking back at Kowhiti Atarau 2013 is there one thing that stands out in your mind?}

The most wonderful buzz for me was coming to the finale of the schools matinee show, and the incredible hoop dance by our Dancing Earth whānau that was shared with our enthusiastic audience to complete the performance. It was such an amazing way to finish the show, and set up the platform for a wonderful Native American workshop for the lucky student recipients afterwards.

\section{What were your intentions with Kowhiti Atarau? What did you want it to be?}

To provide a platform to showcase where indigenous contemporary dance was heading, and the developments in the practices that have been guiding people's works for our dance community to experience. I felt that we certainly demonstrated the numerous methods, technologies and spirit that groups from around the world and nationally are working with. We are a modern dance community that is connected with its heritage. 


\section{Was Kowhiti Atarau different in any way, positive or negative than what you wanted it to be?}

It certainly was a big undertaking to combine the performance season, workshops and forums with the Academic Symposium, but looking back on it all with time to reflect, I felt we achieved a momentous coming together of our international and national dancing communities. It was wonderful to share the stage with fellow artists from Turtle Island (USA), and the Torres Strait Islands, as well as have people from Britain and Hawaii make the trip to $\mathrm{NZ}$ to be a part of the academic conference.

\section{Were such matters as the venues, the time of the year or the scheduling of papers satisfactory to you?}

The time of year worked well in that we were able to partner with Dance Wellington to be the opening event of their inaugural festival.

The increased costs of hiring the Opera House is making it much more prohibitive to contemplate undertaking a forum and show of this scale, as the overheads are extremely high. It may need to look for a smaller venue again for the performances. (Although it will mean less school students can attend the school matinees).

Whitireia was the ideal spot to open the Academic Symposium, and it might have worked out better to host it there for the two days (due to their fantastic sponsorship), and have only 1 paper delivered at a time with the academic symposium attendees not having to choose between different paper options.

\section{5 comment if you want to on the combination of practitioners and academics at Kowhiti Atarau}

Due to the requirements to tech and prepare the main stage show at the Opera House, there wasn't the opportunity for the 
physical dancers to mix as much with the academic attendees. We could hold the academic symposium, followed by the performance events (and workshops), but it would make a 3 day festival into a 5-6 day festival, and the extra accommodation and food costs would probably make the registration costs prohibitive for individuals and Koowhiti Productions respectively.

\section{What for you was the learning in Kowhiti Atarau?}

To see how other cultures stay beautifully connected to their indigenous roots and have a profound connection that is presented throughout their daily lives. This was very inspiring to be around, and although we were incredibly busy coordinating the whole project, one could take some time to observe and reflect on other groups processes. (I wish I had more time to do this however, but the list of jobs was a big one to get through)! :)

\section{Are there any other points you might like to make?}

It was a lovely signing off for me that we were able to offer Suzanne Renner our $5^{\text {th }}$ Kōwhiti lifetime achievement award. Stephen Bradshaw, Tama Huata (who has just passed away Moe mai ra e te rangatira), Gaylene Sciascia and Taiaroa Royal and Suzanne have been our long term kaiarahi in the field of Maori Contemporary Dance Performance. That we were able to acknowledge these tuākana by their tēina, has made me feel satisfied that we have acknowledged them from our community also.

\section{Where to now for Kowhiti?}

We are all focusing on other projects currently, as the work required to bring Kōwhiti to life makes it very difficult to also build one's own work. I am working hard towards presenting Tiki Taane Mahuta (which I presented a pilot version at 
Kōwhiti) at the Isaac Theatre Royal in Christchurch in May 79, 2015. It will be a humbling opportunity to birth this new work to life, as it has been gestating inside for 7 years now.

Naaku noa iti nei

Tanemahuta Gray 